\title{
Comparison of tablets and paper discs for antibiotic sensitivity testing
}

\author{
D. F. J. BROWN ${ }^{1}$ AND D. KOTHARI \\ From the Division of Hospital Infection, Clinical Research Centre, Harrow and the Cross-Infection \\ Reference Laboratory, Central Public Health Laboratory, Colindale, London
}

SYNOPSIS The value of tablets and paper discs as reservoirs of antimicrobial agents for use in sensitivity testing was compared. Antibiotics that were unstable in paper discs showed no demonstrable loss of activity in tablets over a period of 50 days under adverse storage conditions. The antibiotic content of commercially prepared tablets is very high in comparison with the accepted content of paper discs used in Britain, but not all of the agent is released from tablets during tests. Comparison of the size of zones of inhibition around tablets and standard paper discs indicated that the amount of the various agents released from the tablets varied between $2.6 \%$ and $69 \%$ of the stated content. In tests of the sensitivity of a range of common pathogenic organisms, the results obtained with the tablet method-when interpreted as recommended by the manufacturerwere generally similar to those obtained with a paper disc method commonly used in British laboratories. In $47 \%$ of tests with aminoglycoside antibiotics, however, strains sensitive by the disc method were 'intermediate' or resistant by the tablet method. As with paper discs, it was necessary to press the tablets on to the medium. With adjustment of the 'effective' antibiotic content of tablets to bring it into line with the accepted content in paper discs, the stability of antibiotics in the tablets might make them an acceptable alternative to paper discs.

Tablets have been largely replaced by paper discs as reservoirs of antibiotic for use in sensitivity testing. Paper discs are more convenient and easier to produce and handle than tablets and do not crumble in use. Tablets are still available, and several advantages over paper discs are now claimed by one manufacturer (A/S Rosco). Hill (1966) suggested that tablets were more reliable in their antibiotic content than paper discs. Several antibiotics, especially the semisynthetic penicillins and cephalosporins, are unstable in paper discs, and these must be carefully stored at low temperature in the presence of a desiccant if deterioration is to be avoided (Griffith and Mullins, 1968; Ericsson and Sherris, 1971; Drew et al, 1972). One maker (A/S Rosco) claims a shelf life of four years at room temperature for all tablets except carbenicillin. This is said to be because the manufacturing process is dry, in contrast with the wet process used to impregnate paper discs with antibiotic.

We have investigated the stability of antibiotic 1Present address: Microbiology Quality Control Laboratory, Neasden Hospital, Brentfield Road, London NW10 8EY

Received for publication 4 June 1975 tablets manufactured by $\mathbf{A} / \mathrm{S}$ Rosco in comparison with that of paper discs. The stated antibiotic content of the tablets is far higher than is commonly used in paper discs. This might lead to incorrect interpretation for many antibiotics if the tablets were used in accepted British methods; the relationship between the size of the zones of inhibition around tablets and discs was therefore also studied. The results obtained by the tablet sensitivity-test method recommended by A/S Rosco (Casals and Pedersen, 1974) and by a disc method have been compared. Technical advantages and problems encountered in the use of tablets have also been noted.

\section{Material and Methods}

Mueller-Hinton agar (Difco 0252) was used in all experiments. Antibiotic tablets (Neo-Sensitabs) and a dispenser were provided by A/S Rosco, DK-2630 Taastrup, Denmark. Organisms were obtained from the National Collection of Type Cultures, Colindale, London, from the Cross-Infection Reference Laboratory, Colindale, London, from Miss P. M. Waterworth, University College Hospital, London, 
and from the Department of Microbiology, Northwick Park Hospital, Harrow.

DETERIORATION OF ANTIBIOTICS IN TABLETS AND PAPER DISCS

This was compared by leaving discs (AB Biodisk) and tablets containing the same antibiotic together in a sterile Petri dish on the laboratory bench. The antibiotic content of the tablets and discs is shown in figures 1 and 2 . At 2 to 3 day intervals up to 50 days, tablets and discs were removed for testing. At each testing, tablets and discs in duplicate were placed on Mueller-Hinton agar previously seeded by flooding with a suspension of the Oxford Staphylococcus aureus (NCTC No. 6571). The density of the suspension was adjusted to give semiconfluent growth of colonies on the plates after overnight incubation at $37^{\circ} \mathrm{C}$, when the diameters of the zones of inhibition were measured with sliding calipers. Before the experiment discs had been stored in unopened vials at $-20^{\circ} \mathrm{C}$, and some of the discs from the same vial as the discs in the Petri dishes were stored at $-20^{\circ} \mathrm{C}$ during the experiment for testing at the end of the experiment. Tablets were stored, as recommended by the makers, at room temperature (except carbenicillin, stored at $4^{\circ} \mathrm{C}$ ), and some of the tablets from the same vials as the tablets in the Petri dishes were kept in the vials during the experiment for testing at the end of the experiment.

NEO-SENSITABS METHOD (A/S Rosco)

Mueller-Hinton agar was prepared and sterilized as

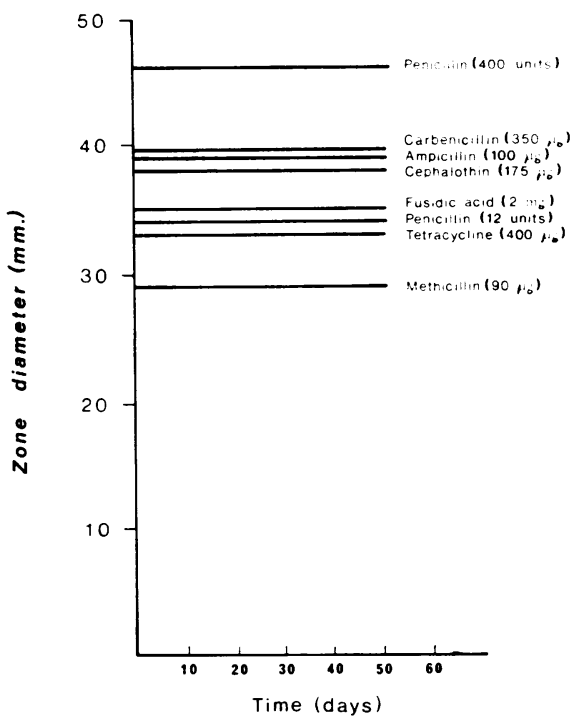

Fig 1 Zones of inhibition of the Oxford Staph. aureus with antibiotic tablets stored under adverse conditions. directed by the makers. The cooled medium was poured into $9 \mathrm{~cm}$ Petri dishes to a depth of $5 \mathrm{~mm}$. The plates were inoculated by flooding the surface of the medium with a suspension of the organisms $\stackrel{\vec{s}}{\vec{s}}$ diluted from an overnight nutrient broth culture too a density giving semiconfluent growth of colonies on the plates after overnight incubation. The $\overline{\bar{c}}$ inoculated plates were dried at $37^{\circ} \mathrm{C}$ for 30 minutes $\overparen{\otimes}$ before tablets were applied. Plates were incubated overnight at $37^{\circ} \mathrm{C}\left(30^{\circ} \mathrm{C}\right.$ for methicillin), and zones ${ }^{\infty}$ of inhibition were measured with sliding calipers $\vec{\circ}$ and dark-ground illumination. Zones were inter- $\overrightarrow{\vec{H}}$ preted from a table (Casals and Pedersen, 1974).

THE PAPER-DISC METHOD

This method was recommended by the Association $\infty$ of Clinical Pathologists (Stokes and Waterworth, $\vec{N}$ 1972). Lysed horse blood $5 \%$ was added to the Mueller-Hinton medium for tests with sulphona- $\omega$ mides and trimethoprim, and the medium was dried $\mathrm{O}$ at $37^{\circ} \mathrm{C}$ for 30 minutes before plates were inoculated. $\overrightarrow{ }$ This was done by flooding with a suspension of $\mathbb{D}$

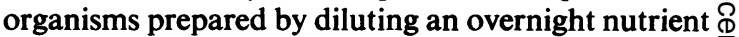
broth culture to a density that gave semiconfluent $\stackrel{3}{3}$ growth of colonies on the plates after overnight $\stackrel{\Phi}{-}$ incubation at $37^{\circ} \mathrm{C}$. After the medium had dried, $\vec{\bullet}$ paper discs (Oxoid) were applied and plates wege or incubated overnight at $37^{\circ} \mathrm{C}$. The control organisins Staph. aureus NCTC No. 6571, Escherichia co NCTC No. 10418, and Pseudomonas aerugino $\overrightarrow{s a}$ NCTC No. 10662 were used as appropriate. Inter-

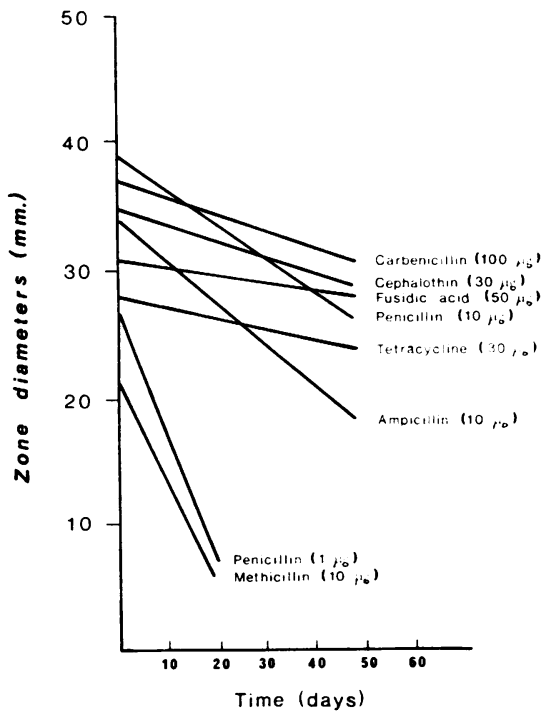

Fig 2 Zones of inhibition of the Oxford Staph. aureus with antibiotic discs stored under adverse conditions. 
pretation was according to the criteria recommended by the Association of Clinical Pathologists.

RELEASE OF ANTIBIOTICS FROM TABLETS

This was studied by assay of tablets against standard paper discs containing known amounts of antibiotics. Standard discs were prepared by dropping $0.01 \mathrm{ml}$ of antibiotic solution of the appropriate concentration on to sterile $6 \mathrm{~mm}$ discs punched from Whatman No. 1 filter paper. The discs were dried at $37^{\circ} \mathrm{C}$ for 30 minutes before use. The sulphonamide in the tablets, sulphamethizole, is not used in discs in Britain so these tablets were assayed against sulphamethoxazole. Mueller-Hinton medium $150 \mathrm{ml}$ was poured into $23.5 \mathrm{~cm}$ Bioassay plates (Nunc: UK agents Jobling). Plates were seeded by an agar overlay method. Melted and cooled Mueller-Hinton agar $50 \mathrm{ml}$ containing a suspension of the assay organism in a concentration to give semiconfluent growth after overnight incubation at $37^{\circ} \mathrm{C}$ was poured over the warmed base layer and allowed to set. The assay organisms used are indicated in table I. The plates were dried before standard discs and tablets (4 tablets of each antibiotic) were applied. A series of four standard discs with two-fold differences in antibiotic content was used in duplicate for each antibiotic. All the standard discs and tablets of a particular antibiotic could be accommodated on one plate without confluence of inhibition zones. Zone diameters were measured, standard curves were plotted, and the amount of antibiotic released from tablets relative to discs was read off from the standard curves.

\section{EFFECT OF PRESSING TABLETS ON TO THE MEDIUM}

After application from a dispenser the effect of pressing tablets on to the medium was studied on Mueller-Hinton medium flooded with a suspension of organisms diluted to a density giving semiconfluent growth of colonies on the plate after overnight incubation at $37^{\circ} \mathrm{C}$. The organisms used are indicated in table III. For each antibiotic, four tablets were applied from a dispenser to 10 similar agar plates seeded with the indicated microorganisms. On each plate two tablets were pressed with sterile forceps to ensure close contact with the medium and the other two were left as they had fallen from the dispenser. After overnight incubation of the plates at $37^{\circ} \mathrm{C}$ the diameters of the inhibition zones were measured.

MINIMUM INHIBITORY CONCENTRATION

(MIC) DETERMINATIONS

MICs were performed by the agar dilution method.

Twofold dilutions of antimicrobial agents were incorporated into Mueller-Hinton agar (Difco 0252) in $9 \mathrm{~cm}$ Petri dishes. Plates were inoculated using a multipoint inoculator. Inocula were prepared by diluting overnight nutrient broth cultures (blood broth for streptococci) 1:5000 for Gram-negative organisms, 1:1000 for staphylococci, and 1:100 for streptococci. Plates were incubated overnight at $37^{\circ} \mathrm{C}\left(30^{\circ} \mathrm{C}\right.$ for methicillin) and the endpoint was read as the lowest concentration of the agent completely inhibiting growth.

\section{Results}

DETERIORATION DURING STORAGE

The zones produced against Staph. aureus NCTC No. 6571 by discs and tablets stored under identical adverse conditions are represented graphically in figures 1 and 2. Deterioration of antibiotics as indicated by reduced zone sizes was not found with any of the tablets; and tablets stored in sealed containers for the duration of the experiment gave zones of similar size to those given by tablets left on the laboratory bench in Petri dishes for 50 days. However, deterioration of antibiotics in discs was evident with all discs tested. After 20 days, methicillin $10 \mu \mathrm{g}$ and penicillin $1 \mu \mathrm{g}$ discs had no demonstrable activity. After 50 days, discs stored at $-20^{\circ} \mathrm{C}$ in sealed vials containing a desiccant gave zones of similar size to zones obtained at the beginning of the experiment with discs that subsequently deteriorated at room temperature.

EFFECTIVE DRUG CONTENT OF TABLETS The results of assay of the tablets against standard paper discs are shown in table I. The amount of drug released from the tablets corresponded to from $2.6 \%$ (nitrofurantoin) to $69 \%$ (penicillin, low-content disc) of the stated content. The amount released relative to disc content was closer to the stated tablet content for the more diffusible antibiotics, such as penicillin, and for tablets of lower antibiotic content, for example, penicillin 12-unit tablets released the equivalent of $69 \%$ of the stated content, while the penicillin 400-unit tablets released the equivalent of $25 \%$ of the stated content.

\section{DIFFERENCES IN INTERPRETATION}

The numbers of times interpretation varied between the disc method and the Neo-Sensitabs tablet method are shown in table II. Generally the differences were minor, although there was a tendency for strains to be categorized as more resistant by the tablet than by the disc method. This was particularly evident with aminoglycoside antibiotics, against which 30 out of 66 sensitive strains (as indicated by MIC) were 
Table I 'Effective' drug content of tablets assayed against standard discs

classified as sensitive by the disc method but 'intermediate' ( 24 tests) or resistant ( 6 tests) by the tablet method. In tests of sensitivity to trimethoprim and co-trimoxazole, four strains were sensitive by the tablet method but were 'intermediate' or resistant by the disc method. Some major differences in interpretation were found, but apart from four strains of Staph. aureus (kanamycin MICs $2-8 \mu \mathrm{g} / \mathrm{ml}$ ) sensitive to kanamycin by the disc method but resistant by the tablet method, and two strains of Ps. aeruginosa (gentamicin MICs 1 and $2 \mu \mathrm{g} / \mathrm{ml}$ respectively) sensitive to gentamicin by the disc method but resistant by the tablet method, these were confined to individual strains.
EFFECT OF PRESSING THE TABLETS ON THE MEDIUM

The results are shown in table III. For four of the 12 antibiotics tested, zone diameters were significantly smaller when the tablets were not pressed on the medium $(P<0.05)$. For nine out of 12 antibiotics the standard deviation of the 20 replicat 8 tests was greater when the tablets were not presse on the medium. For penicillin tablets the standare deviation was three times greater when the tablets were not pressed.

When the dispenser was used there was a small amount of mechanical abrasion of the tablets, leading to accumulation of tablet dust in the

\begin{tabular}{|c|c|c|c|c|}
\hline \multirow[t]{2}{*}{ Antimicrobial Agent } & \multicolumn{4}{|c|}{ Minor and (Major) Differences ${ }^{1}$ in Interpretation between Methods in Tests on } \\
\hline & Staphylococci (15 strains) & $\begin{array}{l}\text { Gram-negative Organisms } \\
\text { excluding Pseudomonads } \\
\text { (12 strains) }\end{array}$ & Streptococci (10 strains) & Pseudomonads (9 strains) \\
\hline $\begin{array}{l}\text { Penicillin } \\
\text { Ampicillin } \\
\text { Cephalothin } \\
\text { Methicillin } \\
\text { Carbenicillin } \\
\text { Tetracycline } \\
\text { Erythromycin } \\
\text { Lincomycin } \\
\text { Kanamycin } \\
\text { Gentamicin } \\
\text { Streptomycin } \\
\text { Fusidic acid } \\
\text { Colistin } \\
\text { Nalidixic acid } \\
\text { Nitrofurantoin } \\
\text { Sulphonamide } \\
\text { Trimethoprim } \\
\text { Co-trimoxazole }\end{array}$ & $\begin{array}{l}0(0) \\
\cdots \\
\ddot{2}(0) \\
\ddot{1}(0) \\
3(0) \\
2(0) \\
7(4) \\
4(0) \\
4(0) \\
0(0) \\
\cdots \\
\ddot{1}(1) \\
1(1) \\
2(1) \\
6(0)\end{array}$ & $\begin{array}{l}\ddot{0}(0) \\
1(0) \\
\cdots \\
\ddot{1}(0) \\
\cdots \\
\ddot{5}(0) \\
0(0) \\
3(0) \\
\cdots \\
\ddot{0}(0) \\
5(1) \\
2(0) \\
1(0) \\
1(0)\end{array}$ & $\begin{array}{l}2(0) \\
\ddot{1}(0) \\
. \\
\ddot{2}(1) \\
2(0) \\
1(0) \\
\ldots \\
. \\
\ldots \\
\ldots \\
\ldots \\
\ldots \\
\ddot{0}(1) \\
. \\
.\end{array}$ & 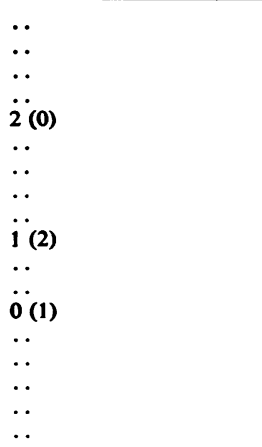 \\
\hline
\end{tabular}

Table II Occurrence of differences in interpretation between paper disc and tablet methods

${ }^{1}$ Minor difference $=$ difference between 'intermediate' and sensitive or resistant

Major difference $=$ difference between sensitive and resistant 


\begin{tabular}{|c|c|c|c|c|}
\hline \multirow[t]{2}{*}{ Antimicrobial Agent } & \multirow[t]{2}{*}{ Test Organism } & \multicolumn{2}{|c|}{ Standard Deviation of 20 Replicate Observations } & \multirow{2}{*}{$\mathbf{P}$} \\
\hline & & Tablets pressed & Tablets not pressed & \\
\hline $\begin{array}{l}\text { Penicillin (high) } \\
\text { Carbenicillin } \\
\text { Gentamicin } \\
\text { Kanamycin } \\
\text { Streptomycin } \\
\text { Erythromycin } \\
\text { Lincomycin } \\
\text { Nalidixic acid } \\
\text { Nitrofurantoin } \\
\text { Fusidic acid } \\
\text { Polymyxin B } \\
\text { Co-trimoxazole }\end{array}$ & $\begin{array}{l}\text { Staph. aureus } \\
\text { E. coli } \\
\text { Staph. aureus } \\
\text { Staph. aureus } \\
\text { E. coli } \\
\text { Staph. aureus } \\
\text { Staph. aureus } \\
\text { E. coli } \\
\text { E. coli } \\
\text { Staph. aureus } \\
\text { E. coli } \\
\text { E. coli }\end{array}$ & $\begin{array}{l}0.483 \\
0.347 \\
0.668 \\
0.532 \\
0.528 \\
0.509 \\
0.794 \\
1.072 \\
0.304 \\
1.093 \\
0.654 \\
0.920\end{array}$ & $\begin{array}{l}1.497 \\
0.373 \\
1.025 \\
0.807 \\
0.421 \\
0.844 \\
1.622 \\
1.606 \\
0.639 \\
1.063 \\
0.632 \\
1.634\end{array}$ & $\begin{array}{l}<0.05 \\
>0.05 \\
>0.05 \\
<0.05 \\
>0.05 \\
<0.05 \\
>0.05 \\
>0.05 \\
<0.05 \\
>0.05 \\
>0.05 \\
>0.05\end{array}$ \\
\hline
\end{tabular}

Table III Effect of pressing tablets on to medium after tablets had been applied from a dispenser

dispenser; and carelessness in loading the dispenser sometimes resulted in crushing of tablets, but the dispenser was easily dismantled for cleaning. Whether a dispenser or forceps were used to put tablets on the medium, tablets occasionally fell off when plates were incubated in an inverted position.

\section{Discussion}

The poor keeping quality of some antibiotic discs necessitates careful storage if loss of potency is to be avoided. The greatest advantage of tablets over discs, if the maker's claims were to be substantiated, would be the stability of antibiotics in the tablets, eliminating the need for special storage and handling in busy routine microbiology laboratories. The claims were substantiated during seven weeks of exposure to the atmosphere on a laboratory bench; loss of activity could not be demonstrated with any of the antibiotic tablets tested, while all of the discs showed some loss of potency. The makers recommend that carbenicillin tablets be stored at $4^{\circ} \mathrm{C}$ as this antibiotic is not as stable as others in tablets, yet loss of activity was not demonstrable with carbenicillin tablets over 50 days in a relatively warm and humid atmosphere. In a description of the manufacture and control of Neo-Sensitabs, Pedersen (1973) claimed that loss of potency of antibiotics was not observed in tablets stored at $25^{\circ} \mathrm{C}$ without a desiccant for three years. He stated that the stability of the tablets was due to the dry manufacturing process, the crystal size of the antibiotics, and the solubility of the active substances contained in the tablets, also, the maker's claim that the inactive granulate, which comprises the main bulk of the tablets, protects the active agent.

The stated antibiotic content of tablets is considerably higher than the content of discs commonly used in British laboratories (as much as 200 times with some antibiotics) yet the zones of inhibition were not as large as might have been expected. The results of assays against standard paper discs indicated much lower effective antibiotic content of tablets than declared on the labels, but still higher than would commonly be used in British laboratories. Either all the agent is not released from the tablets or antibiotics are inactivated or chemically bound to other materials in the tablets. Pedersen (1973) used a spectrophotometric method to estimate active ampicillin extracted from tablets and found tablets to contain between $85 \%$ and $125 \%$ of declared contents, so inactivation is unlikely. Thus, the tablets could not be substituted for discs in recognized British methods of antibiotic sensitivity testing because the higher effective antibiotic contents would result in a number of falsely sensitive results. On the other hand, the results of tests obtained by the method given by the makers of the tablets, when interpreted according to the table given by Casals and Pedersen (1974), were very similar to those obtained by a disc method commonly used by British laboratories.

The dispenser allowed rapid application of tablets to the surface of the medium, the weight and consistent size of the tablets being suited to the use of a dispenser. However, after application of the tablets it is necessary to press them gently to ensure close adherence to the medium, as with paper discs (Griffith and Mullins, 1968). Failure to press tablets on to the medium would result in reduced zone sizes and possibly lead to false reports of resistance.

If the tablets could be marketed at a price competitive with that of paper discs they would be an attractive alternative to discs. With the present tablets, however, the interpretation of the zone size would have to be made according to a different scale from that commonly used in British laboratories, and this might lead to confusion. Also the width of zones would increase the number or size of agar plates used. Alternatively, the manufacturers might 
be prepared to alter the antibiotic contents of their tablets so that the zones of inhibition corresponded to those given by paper discs of conventional antibiotic content.

We are grateful to Dr. R. Blowers and Dr. M. T. Parker for helpful criticism.

\section{References}

Casals, B. J. and Pedersen, O. G. (1974). Nouvelle technique pour antibiogrammes. A/S Rosco literature.

Drew, W. L., Barry, A. L., O'Toole, R., and Sherris, J. C.
(1972). Reliability of the Kirby-Bauer disc diffusion method for detecting methicillin-resistant strains of $\stackrel{\mathscr{P}}{\overrightarrow{2}}$ Staphylococcus aureus. Appl. Microbiol., 24, 240-247.

Ericsson, H. snd Sherris, J. C. (1971). Antibiotic sensitivity testing. Report of an International Collaborative Study. Acta. path. microbiol. scand., Sect. B Suppl. No. 217.

Griffith, L. J. and Mullins, C. G. (1968). Drug resistance as influenced by inactivated sensitivity discs. Appl. Microbiol., 16, 656-658.

Hill, G. H. (1966). Some aspects of antibiotic sensitivity testing. N.Z. J. med. Lab. Technol., 20, 70-75.

Pedersen, O. G. (1973). Standardising manufacture and control of Neo-Sensitabs. Acta clin. belg., 28, 139-149.

Stokes, E. J. and Waterworth, P. M. (1972). Antibiotic sensitivity tests by diffusion methods. Broadsheet No. 55, (revised). Association of Clinical Pathologists, London. 